\title{
Foeniculum vulgare Mill (Umbelliferae) Attenuates Stress and Improves Memory in Wister Rats
}

\author{
Sushruta Koppula* and Hemant Kumar \\ College of Biomedical and Health Sciences, Department of Biotechnology, Konkuk University, Chungju, Republic of Korea.
}

*For correspondence: Email: koppula@kku.ac.kr; Tel: +82-43-840-3609; Fax: +82-43-852-3616.

\begin{abstract}
Purpose: To evaluate the anti-stress and memory-enhancing properties of $F$. vulgare extract in experimental rats.

Methods: F. vulgare plant extract was obtained using Soxhlet extraction technique. The extract, at doses of 50, 100 and $200 \mathrm{mg} / \mathrm{kg}$ body weight, was administered orally with an orogastric tube. Urinary levels of vanillylmandelic acid (VMA) and ascorbic acid in rats were used to evaluate anti-stress activity. Conditioned avoidance response was measured in normal and scopolamine-induced amnesic rats to study the memory-enhancing effects. Lipid peroxidation inhibition assay in liver and brain homogenates of rats was used to evaluate antioxidant activity.

Results: Daily administration of $F$. vulgare extract (50, 100 and $200 \mathrm{mg} / \mathrm{kg}$ body weight) $1 \mathrm{~h}$ prior to induction of stress significantly $(p<0.05)$ altered the stress-induced urinary biochemical levels of VMA from $395.79 \pm 11.23$ to $347.12 \pm 12.28,311.21 \pm 12.48$ and $258.86 \pm 10.26 \mu \mathrm{g} / \mathrm{kg}$, respectively, in $24 \mathrm{~h}$, as well as ascorbic acid excretion levels from $65.74 \pm 9.42$ to $78.59 \pm 8.44,108.41 \pm 15.62$ and 125.82 $\pm 16.94 \mu \mathrm{g} / \mathrm{kg}$ also within the same period, respectively. These changes occurred in a dose-dependent fashion, and the levels in the control groups were unchanged within the same period. The memory deficits induced by scopolamine (1 $\mathrm{mg} / \mathrm{kg}$, i.p.) in rats was reversed by F. vulgare dose-dependently. The extract also exhibited potent antioxidant effect by inhibition of lipid peroxidation in both rat liver and brain homogenates to a greater extent than the standard antioxidant, ascorbic acid.

Conclusion: F. vulgare may be useful in the management of stress and stress-related disorders on account of its multiple actions such as anti-stress, memory-enhancing and antioxidant effects.

Keywords: Foeniculum vulgare, Stress, Vanillyl mandelate, Memory, Antioxidant, Ascorbic acid

Tropical Journal of Pharmaceutical Research is indexed by Science Citation Index (SciSearch), Scopus, International Pharmaceutical Abstract, Chemical Abstracts, Embase, Index Copernicus, EBSCO, African Index Medicus, JournalSeek, Journal Citation Reports/Science Edition, Directory of Open Access Journals (DOAJ), African Journal Online, Bioline International, Open-J-Gate and Pharmacy Abstracts
\end{abstract}

\section{INTRODUCTION}

Every individual experiences stress, a pattern of metabolic and behavioral reactions in response to external and internal stimuli. Extreme stress may cause threatened homeostasis leading to the pathogenesis of a variety of disease conditions including depression, anxiety, immunosuppression, endocrine disorders, cognitive dysfunction, peptic ulcer, hypertension and reproductive dysfunctions [1]. Stress effects brain function, impairs memory and disrupts cognitive skills leading to the pathogenesis of various central nervous system diseases [2]. Extreme stress builds up free radicals and induces potential damage to neuronal receptors and a variety of other tissues [3]. Therefore agents that inhibit free radicals may have great potential in mitigation of stress and stressinduced diseases.

Drug and food from natural origin play a significant role in the public healthcare systems and are being investigated as remedies for number of stress-related disorders [4]. Spices 
and condiments used in culinary practices to impart flavor, color and nutritional values in food are also being used to treat various diseases in traditional medicines [5]. In particular, spices from Umbelliferae family have been reported to possess immense pharmacological benefits [68]. Foeniculum vulgare Mill. (Umbelliferae, $F$. vulgare), commonly known as fennel is a well known medicinal and aromatic plant widely used as carminative, digestive, lactogogue, diuretic and in treating respiratory and gastrointestinal disorders [9]. Pharmacologically, F. vulgare has been shown to possess anti-inflammatory [10], anti-diabetic [6], anti-bacterial [11], anti-fungal [12], anti-oxidant [13], analgesic [14], estrogenic [15], hepatoprotective [16], and anti-tumor activities [17].

The major chemical components of $F$. vulgare are flavonoids, polyphenols, carotenoids, minerals and vitamins. The fruit of $F$. vulgare contains components like estragole, fenchone, alpha-phellandrene and aglycons $[18,19]$.

Despite the potential biological activities presented by $F$. vulgare, the stress-relieving and memory-enhancing effect shave not been studied. In the present study, we evaluated the anti-stress and memory-enhancing activities of $F$. vulgare extract in experimental rat models. In addition, we evaluated the antioxidant defense potential of $F$. vulgare extract to see if it correlates with its anti-stress and memory enhancing effects in rat liver and brain homogenates.

\section{EXPERIMENTAL}

\section{Chemicals}

Vanillylmandelic acid (VMA) and scopolamine butyl bromide (SBB) were purchased form Sigma Chemical Company, St. Louis, MO, USA. Ascorbic acid was purchased from Loba Chemie, Mumbai, India. All other reagents used were of analytical grade. Stock solutions of all chemicals were prepared in distilled water and the dilutions were made fresh on the day of the experiment.

\section{Preparation of extract}

Dried fruit material of $F$. vulgare $(1 \mathrm{~kg})$ was obtained from a local market in Vijayawada, India. Dr K Hemadri, a taxonomist at Regional Research Institute, India, confirmed the authenticity of the fruit material and a voucher specimen (FV-2004) was kept in our department herbarium for future reference. The material was powdered and extracted with boiling water $(5 \mathrm{~L})$ for $30 \mathrm{~min}$ by Soxhlet technique. The filtrate was evaporated at $<70{ }^{\circ} \mathrm{C}$ in a vacuum dryer to give a final yield of $98.74 \mathrm{~g}$. $F$. Vulgare was completely solubilized in distilled water for use in in vivo and in vitro experiments respectively

\section{Animals}

Wistar rats of either sex, obtained from Ghosh Enterprises, Kolkata were housed in an airconditioned animal room at $23 \pm 2^{\circ} \mathrm{C}$ with $12 / 12 \mathrm{~h}$ light/ dark photoperiod, and free access to water and laboratory rat chow. The animals were kept for seven days in laboratory for habituation. All animal experiments were performed in accordance and approval with our Institutional Animal Ethics Committee (Regd. No. 516/01/A/CPCSEA) following the guidelines of the Committee for the Purpose of Control and Supervision of Experiments on Animals (CPCSEA), Government of India and the International Guidelines for Handling of Laboratory Animals [20].

\section{Evaluation of anti-stress activity}

Induction of stress was carried out using the forced swimming test in rats [21]. The animals were divided into four groups, each consisting of six animals of either sex, in metabolic cages that were designed to facilitate the collection of urine. $24 \mathrm{~h}$ urine samples from each group were collected into two different beakers using an inverted ' $Y$ ' tube fixed at the bottom of each metabolic cage. One end of the tube received urine into a beaker containing $5 \mathrm{ml}$ of $10 \%$ oxalic acid and then passed on for spectrophotometric determination of ascorbic acid at $550 \mathrm{~nm}$. The other end of the tube received and moved urine into a beaker containing $0.5 \mathrm{ml}$ of $6 \mathrm{~N}$ hydrochloric acid for determination of vanillylmandellic acid (VMA) spectrophotometrically at $360 \mathrm{~nm}$. The experimental protocol followed was as described previously [8].

\section{Evaluation of memory enhancing activity}

This experiment was evaluated by conditioned avoidance response (CAR) technique in rats using Cook's pole climbing apparatus (Techno, India). Briefly, rats were divided into 4 groups of 5 animals each. Groups II, III and IV were administered orally with 50, 100 and $200 \mathrm{mg} / \mathrm{kg}$, respectively of $F$. vulgare extract (dissolved in distilled water) while animals in group I were served as control and received only distilled water. After 90 minutes, all the animals were subjected to a training schedule individually by placing them inside the Perspex chamber of the apparatus. After an acclimatization period of 5 min in the chamber, a buzzer was given followed 
by a shock through the grid floor. The rat had to jump on to the pole (shock-free zone) to avoid foot shock. Jumping on the pole functionally terminates the shock and this was classified as an escape while such jumping prior to the onset of the shock was considered as avoidance. The session was terminated after completion of 60 trials with an interval of 20-30 seconds between trials. This procedure was repeated at $24 \mathrm{~h}$ intervals until all groups reach 95 to $99 \%$ avoidance. Following the attainment of complete training for a particular group, the animals were treated with a single dose of scopolamine butyl bromide (1 $\mathrm{mg} / \mathrm{kg}$, i.p.) to induce amnesia, 30 min before the next day dosing with the extract. The training schedule was continued further with the daily doses of the extract and vehicle until the rats returned to normal level from scopolamineinduced amnesia.

\section{Determination of thiobarbituric acid-reactive substances (TBARS)}

Rats weighing between 150 - $200 \mathrm{~g}$ were sacrificed by spinal traction. Whole liver and brain were excised and washed in ice-cold Tris$\mathrm{HCl}$ buffer $(0.1 \mathrm{M}, \mathrm{pH} 7.4)$, and cytosolic samples of liver and brain homogenate were prepared separately by using a tissue grinder (Thomas Scientific, NJ, USA) and centrifuging at 10,000 rpm for $30 \mathrm{~min}$ at $4{ }^{\circ} \mathrm{C}$. The TBARS assay was performed as described previously [8]. Briefly, reaction mixture $(0.5 \mathrm{ml})$ containing rat liver homogenate $(0.1 \mathrm{ml}, 25 \% \mathrm{w} / \mathrm{v})$ in Tris- $\mathrm{HCl}$ buffer (40 mM, pH 7.0), KCl (30 mM), ferrous ion (0.16 $\mathrm{mM})$, and ascorbic acid $(0.06 \mathrm{mM})$ were incubated for $1 \mathrm{~h}$ at $37{ }^{\circ} \mathrm{C}$ in the presence and absence of various concentrations of $F$. vulgare extract. The incubation mixtures $(0.4 \mathrm{ml})$ were treated with sodium dodecyl sulfate $(8.1 \%, 0.2$ $\mathrm{ml})$, thiobarbituric acid $(0.8 \%, 1.5 \mathrm{ml})$, and acetic acid $(20 \%, 1.5 \mathrm{ml}, \mathrm{pH} 3.5)$. The total volume was then made up to $4 \mathrm{ml}$ with distilled water and kept in a water bath at $100{ }^{\circ} \mathrm{C}$ for $1 \mathrm{~h}$. On cooling, $1 \mathrm{ml}$ of distilled water and $5 \mathrm{ml}$ of a mixture of $\mathrm{n}$ butanol and pyridine (15:1 v/v) were added and vortexed. After centrifugation, the absorbance of the organic layer was measured at $532 \mathrm{~nm}$. The percentage inhibition of lipid peroxidation was determined by comparing the results of the test compound with those of the control not treated with the extract. The same procedure was followed with rat whole brain homogenate. The $50 \%$ inhibition values were derived from a plot of quantity $(\mu \mathrm{g})$ against absorbance.

\section{Statistical analysis}

The results are expressed as mean \pm SEM. Student's paired $t$-test using GraphPad software was used for statistical analysis. In all cases, $p<$ 0.05 was considered statistically significant.

\section{RESULTS}

\section{F. vulgare extract inhibits stress-induced urinary biochemical changes in rats}

As shown in Figs 1 and 2, a significant increase in urinary levels of VMA $(p<0.001)$, and decrease in ascorbic acid excretion levels ( $p<$ 0.001 ), was observed in animals induced by forced swim stress when compared to the normal basal levels in control animals. The altered levels returned to normal basal levels three to four days after withdrawal of stress. The extract treated groups under normal condition produced no significant change in the excretion of VMA and ascorbic acid compared to basal levels. Treatment with extract (50, 100 and $200 \mathrm{mg} / \mathrm{kg}$ ) one hour prior to the induction of stress significantly inhibited $(p<0.05)$ the increase in urinary VMA levels to $347.12 \pm 12.28,311.21 \pm$ 12.48 and $258.86 \pm 10.26 \mu \mathrm{g} / \mathrm{kg} / 24 \mathrm{~h}$, respectively, in a dose dependent fashion (Fig 1). In contrast, administration of $F$. vulgare extract (50, 100 and $200 \mathrm{mg} / \mathrm{kg}$ ) one hour prior to the induction of stress significantly $(p<0.05)$ and dose dependently inhibited the decrease in ascorbic acid urinary levels to $78.59 \pm 8.44$, $108.41 \pm 15.62$ and $125.82 \pm 16.94 \mu \mathrm{g} / \mathrm{kg} / 24 \mathrm{~h}$, respectively (Fig 2 ).

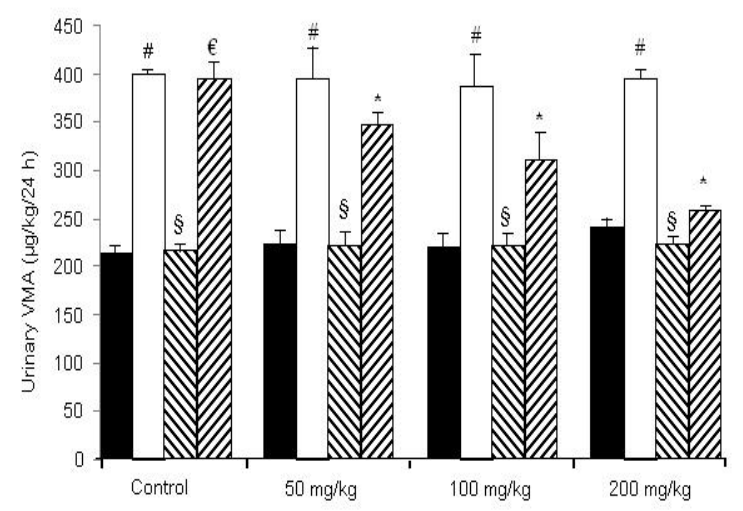

Fig 1: Influence of $F$. vulgare extract on the $24 \mathrm{~h}$ urinary levels of VMA in normal and stress-induced rats (mean \pm S.E.M., $n=6$ );

$=$ Normal, $\square=$ Stress, $\mathbb{N}=$ Normal + F. vulgare and $\square=F$. vulgare + Stress.

${ }^{*} p<0.001$ compared to normal condition of the corresponding groups. ${ }^{*} p<0.05$, compared with stressed condition of the corresponding groups. ${ }^{\S}$ No significant difference compared with normal condition of the corresponding groups. ${ }^{€}$ No significant difference from stressed condition 


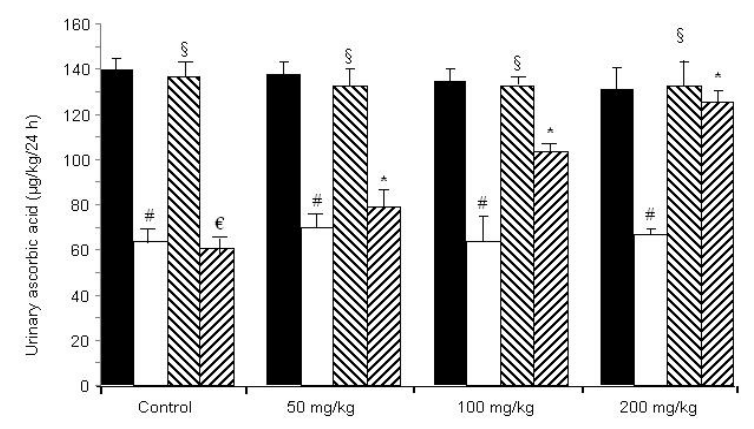

Fig 2: Effect of $F$. vulgare extract on the $24 \mathrm{~h}$ urinary levels of ascorbic acid in normal and stress-induced rats. Data are represented as mean $\pm \operatorname{SEM}(n=6)$. ${ }^{\#} p<$ 0.001 , compared to normal condition of the corresponding groups. ${ }^{*} p<0.05$, compared with stressed condition of the corresponding groups. ${ }^{\S} \mathrm{No}$ significant difference compared with normal condition of the corresponding groups. ${ }^{€}$ No significant difference compared to stressed condition.

$$
\begin{aligned}
& =\text { Normal, } \square \text { Stress, } \quad \mathbb{N} \text { Normal + F. vulgare } \\
& \text { and } \mathbb{Z}=\text { F. vulgare + Stress. }
\end{aligned}
$$

F. vulgare extract attenuates scopolamineinduced amnesia

The CAR of rats administered with the extract increased gradually to $95 \%$ over 7 to 12 days (Fig 3). The acquisition (time to achieve $95 \%$ CAR) for rats administered with the extract was dose- and time-dependent compared to vehicle treated (control) group, which took 12 days for acquisition. The percent avoidance was always higher in the extract treated groups compared to vehicle treated (control) group. Animals receiving $200 \mathrm{mg} / \mathrm{kg}$ body weight of the extract took ten days while groups treated with 100 and $50 \mathrm{mg} / \mathrm{kg}$ doses of the extract required eleven and twelve days, respectively, to reach the point of acquisition. Administration of scopolamine produced amnesia as seen from reduction in the observed CAR. Amnesia was greater in the control group than in extract-treated groups. However, continued treatment with $F$. vulgare produced better retention and recovery in a dose-dependent manner than the vehicle-treated animals. Recovery from scopolamine-induced amnesia in the extract-treated groups took 3-5 days when compared to normal (control) group which took over 6 days.

\section{F. vulgare extract inhibited the lipid peroxidation in rat brain and liver homogenate}

As shown in Fig 4, generation of lipid peroxides by the induction of $\mathrm{Fe}^{2+} /$ ascorbate in rat liver and brain homogenates was inhibited by the extract in a dose-dependent fashion. The inhibition was higher in brain homogenate than in liver, indicating that it is more effective in brain. The quantity of the extract needed for $50 \%$ inhibition of lipid peroxides in rat liver homogenate was $4480 \mu \mathrm{g}$ (Fig 4A). A similar effect was produced by $5350 \mu \mathrm{g}$ of ascorbic acid. The quantity of the extract needed for $50 \%$ inhibition of brain lipid peroxidation was $3670 \mu \mathrm{g}$. A similar effect was produced by $4390 \mu \mathrm{g}$ of ascorbic acid (Fig 4B).

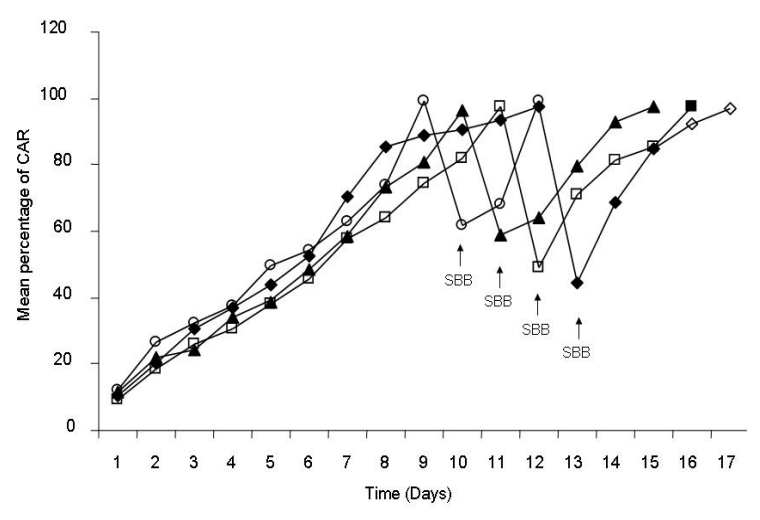

Fig 3: Effect of $F$. vulgare extract on the mean percent of conditioned avoidance response after oral administration in rats. Scopolamine butyl bromide (SBB) was administered $30 \mathrm{~min}$ prior to next day dosing with the extract after attaining complete acquisition. $\bullet=$ Control, $\square=50 \mathrm{mg}, \boldsymbol{\Delta}=100 \mathrm{mg}$ and $\mathrm{o}$ $=200 \mathrm{mg}$.
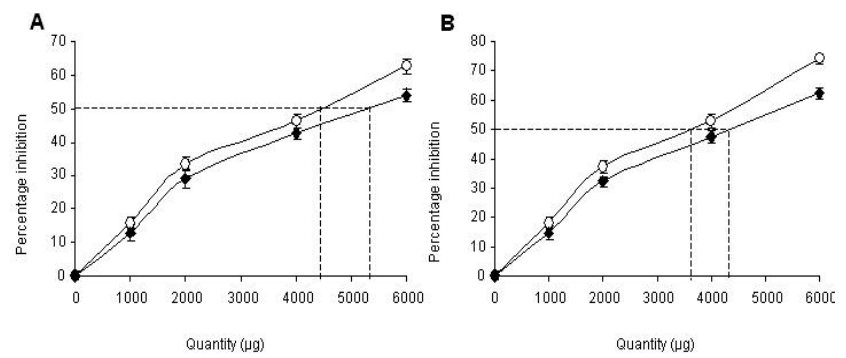

Fig 4: Effect of $F$. vulgare on the in vitro inhibition of lipid peroxidation in liver and brain of rat $(n=6)$ showing the concentrations of $F$. vulgare and ascorbic acid required for 50 percent inhibition of lipid peroxidation in liver $(A)$ and brain $(B)$ homogenates. $O=F$. vulgare and $\bullet=$ ascorbic acid.

\section{DISCUSSION}

In the present investigation $F$. vulgare extract showed significant inhibition of the stressinduced biochemical changes in VMA and ascorbic acid. The memory deficits observed in scopolamine-induced amnesic rats were also attenuated by $F$. vulgare extract. Further, the extract exhibited antioxidant action by inhibition of lipid peroxidation in both liver and brain homogenates of rats.

Mounting evidence suggests that stress induces considerable changes in the neurochemical, 
biochemical and molecular processes [22, 23]. Noradrenaline and adrenaline, which are released normally or in response to stress are metabolized into 3-methoxy 4-hydroxyphenyl glycol (MOPEG) centrally and VMA (the metabolite of adrenaline) peripherally [24]. During increased stress, the blood level of VMA is observed in high concentration, and excreted in the urine [24]. L-ascorbic acid, which is synthesized from D-glucose in rats, is altered in body fluids due to several factors including stress. Ascorbic acid is present in adrenal glands as a metabolite of glucose in rats and glucaric acid is the corresponding metabolite in humans and primates. Studies indicate that the tissue levels of ascorbic acid are decreased on application of stress $[25,26]$. Therefore, in the present study, the increase in the urinary VMA and decrease in the urinary ascorbic acid levels during stress were used as indirect biochemical indices to study the anti-stress activity of $F$. vulgare extract.

Earlier reports revealed that antioxidant herbs might be promising in reducing stress [6, 24, 27]. $F$. vulgare extract scavenged the lipid peroxide free radicals in a concentration dependent manner in both liver and brain homogenates of the rats. The concentration needed for $50 \%$ inhibition of lipid peroxides was lower in brain homogenates when compared to liver homogenates suggesting that $F$. vulgare has potential effects on central nervous system. In both liver and brain homogenates, $F$. vulgare showed higher lipid peroxide inhibition activity than that of a known antioxidant, ascorbic acid.

Stress and free radicals have been shown to affect memory function and processing [28, 29]. It is well documented that scopolamine induction impairs retrieval of memory in rats and such amnesia was associated with a significant increase in oxidative stress [30]. Therefore, scopolamine-induced amnesia in rats could be used as a valid model to screen several antioxidant agents, which may show potential therapeutic benefits in dementia.

In this study, the anti-stress and antioxidant activities of the extract are consistent with the memory-enhancing effects in scopolamineinduced rats. The antioxidant defense mechanism of the extract might be responsible for its anti-stress and memory enhancing activities.

\section{CONCLUSION}

This study provides scientific support for antistress, antioxidant and memory-enhancing activities of F. vulgare extract. Based on our present results and earlier traditional medicinal claims, F. vulgare extract can be developed as a therapeutic agent in the management of stress and stress-related diseases such as memory loss.

\section{ACKNOWLEDGEMENT}

This work was supported by Konkuk University, Chungju, South Korea (2013).

\section{REFERENCES}

1. Boenisch ED, Haney MC. The stress owner's manual. California: Impact Publishers; 2004.

2. Sterlemann V, Rammes G, Wolf M, Liebl C, Ganea K, Müller MB, Schmidt MV. Chronic social stress during adolescence induces cognitive impairment in aged mice. Hippocampus. 2010; 20(4):540-549.

3. Uttara $B$, Singh AV, Zamboni $P$, Mahajan RT. Oxidative stress and neurodegenerative diseases: a review of upstream and downstream antioxidant therapeutic options. Curr Neuropharmac 2009 7: 65-74.

4. Padma $P$, Khosa RL. Anti-stress agents from natural origin. J Nat Rem 2002; 2(1):21- 27.

5. Tapsell LC, Hemphill I, Cobiac L, Patch CS, Sullivan DR, Fenech M, Roodenrys S, Keogh JB, Clifton PM, Williams PG, et al. Health benefits of herbs and spices: the past, the present, the future. Med $J$ 2006; 185: S4-S24.

6. Koppula S, Sreemantula S, Nammi S, Jaladi R. Evaluation of blood glucose reducing effects of aqueous extracts of the selected umbelliferous fruits used in the culinary practices. Trop J Pharm Res 2006; 5(2): 613-617.

7. Koppula S, Kopalli SR, Sreemantula S. Adaptogenic and Nootropic Activities of Aqueous Extracts of Carum Carvi Linn (Caraway) Fruit: An Experimental Study in Wistar Rats. Aus J Med Herb 2009; 21 (3): 7278.

8. Koppula S, Choi DK. Anti-Stress and Anti-Amnesic effects of Coriandrum sativum Linn (Umbelliferae) extract - an experimental study in rats. Trop J Pharm Res 2012; 11(1): 36-42.

9. Agarwal R, Gupta SK, Agarwal SS., Srivastava S, Saxena $R$. Oculohypotensive effects of Foeniculum vulgare in experimental models of glaucoma. Indian $\mathrm{J}$. Physiol. Pharmacol 2008; 52: 77-83.

10. Ostad SN, Soodi $M$, Shariffzadeh $M$, Khorshidi $N$, Marzban $H$. The effect of fennel essential oil on uterine contraction as a model for dysmenorrhea, pharmacology and toxicology study. J. Ethnopharmacol 2001; 76: 299-304.

11. Kaur GJ, Arora DS. In-vitro antibacterial activity of three plants belonging to the family Umbelliferae. Int. J. Antimicrob. Agents 2008; 31: 393-395.

12. Pai MB, Prashant GM, Murlikrishna KS, Shivakumar KM, Chandu GN. Antifungal efficacy of Punica granatum, Acacia nilotica, Cuminum cyminum and Foeniculum vulgare on Candida albicans: an in vitro study. Indian J. Dental Res 2010; 21 (3): 334336.

13. Ruberto G, Baratta MT, Deans SG, Dorman HJD. Antioxidant and antimicrobial activity of Foeniculum vulgare and Crithmum maritimum essential oils. Planta Med 2000; 66: 687-693.

14. Choi EM, Hwang JK. Anti-inflammatory, analgesic and antioxidant activities of the fruit of Foeniculum vulgare. Fitoterapia 2004; 75: 557-565. 
15. Albert-Puleo M. Fennel and anise as estrogen agents. J. Ethnopharmacol 1980; 2: 337-344.

16. Ozbek H, Ugras S, Dulger H, Bayram I, Tuncer I, Ozturk G, Ozturk A. Hepatoprotective effect of Foeniculum vulgare essential oil. Fitoterapia 2003; 74: 317319.

17. Pradhan $M$, Sribhuwaneswari S, Karthikeyan D, Minz S, Sure $P$, Chandu AN, Mishra U, Kamalakannan $K$ Saravanankumar A, Sivakumar T. In-vitro cytoprotection activity of Foeniculum vulgare and Helicteres isora in cultured human blood lymphocytes and antitumour activity against B16F10 melanoma cell line. Res. J. Pharm. Technol 2008; 1 (14): 450-452.

18. Fang L, Qi M, Li T, Shao Q, Fu R. Headspace solvent microextraction-gas chromatography-mass spectrometry for the analysis of volatile compounds from Foeniculum vulgare Mill. J Pharm Biomed Anal 2006; 41(3): 791-797.

19. Singh UP, Singh DP, Maurya S, Maheshwari $R$, Singh $M$, Dubey $R S$, et al. Investigation on the phenolics of some spices having pharmacotherapeuthic properties. J Herb Pharmacother 2004; 4(4): 27-42.

20. Derrell C. "Guide for the care and use of laboratory animals. Institute of laboratory animal resources. National Academy Press, Washington DC, USA 1996.

21. Nagaraja HA, Jaganathan PS. Influence of different types of stress on selected cardiovascular parameters in rats. J Physiol Pharmacol 1999; 43: 296-304.

22. Jiang CG, Morrow-Tesch JL, Beller DI, Levy EM, Black $\mathrm{PH}$. Immunosuppression in mice induced by cold water stress. Brain Behav Immunol 1990; 4: 278291.

23. Ueyama T, Kawai Y, Nemoto K, Sekimoto M, Toné S, Senba E. Immobilization stress reduced the expression of neurotrophins and their receptors in the rat brain. Neurosci Res 1997; 28: 103-110.

24. Sreemantula $S$, Nammi $S$, Kolanukonda $R$, Koppula $S$, Boini KM. Adaptogenic and nootropic activities of aqueous extract of Vitis vinifera (grape seed): an experimental study in rat model. BMC Complement Altern Med 2005; 5:1.

25. Kutlu HR, Forbes JM. Changes in growth and blood parameters in heat stressed broiler chicks in response to dietary ascorbic acid. Liverstock Prod Sci. 1993; 36: 335-350.

26. Goodman GA. The pharmacological basis of therapeutics. (10th ed). McGraw-Hill: New York, 2001; 1804-1805

27. Bhattacharya A, Ghosal S, Bhattacharya SK. Anti-oxidant effect of Withania somnifera glycowithanolides in chronic footshock stress-induced perturbations of oxidative free radical scavenging enzymes and lipid peroxidation in rat frontal cortex and striatum. $J$ Ethnopharmacol 2001; 74:1-6.

28. Jodar L, Takahashi M, Kaneto H. Effects of footshock, psychological- and forced swimming-stress on the learning and memory processes: involvement of opioidergic pathways. Jpn J Pharmacol 1995; 67: 143-147.

29. Esch T, Stefano GB, Fricchione GL, Benson $H$. The role of stress in neurodegenerative diseases and mental disorders. Neuroendocrinol Lett 2002; 23: 199-208.

30. El-Sherbiny DA, Khalifa AE, Attia AS, Eldenshery EI D. Hypericum perforatum extract demonstrates antioxidant properties against elevated rat brain oxidative status induced by amnestic dose of scopolamine. Pharmacol Biochem Behav 2003; 76: 525-533. 